2020-03-25

\title{
Assessing the Correlation of Microscopy-based and Volumetry- based Measurements for Resin Swelling in a Range of Potential Greener Solvents for SPPS
}

Jordan K. Magtaan

Technological University Dublin

Marc Devocelle

Royal College of Surgeons in Ireland

Fintan Kelleher

Technological University Dublin, fintan.kelleher@tudublin.ie

Follow this and additional works at: https://arrow.tudublin.ie/ittsciart

Part of the Medicinal-Pharmaceutical Chemistry Commons, and the Organic Chemistry Commons

\section{Recommended Citation}

Magtaan, J., Devocelle, M. \& Kellerher, F. (2020). Assessing the correlation of microscopy-based and volumetry-based measurements for resin swelling in a range of potential greener solvents for SPPS. Journal of Peptide Science, 26(6),e3250. doi:10.1002/psc.3250

This Article is brought to you for free and open access by the School of Science and Computing at ARROW@TU Dublin. It has been accepted for inclusion in Articles by an authorized administrator of ARROW@TU Dublin. For more information, please contact arrow.admin@tudublin.ie, aisling.coyne@tudublin.ie, gerard.connolly@tudublin.ie.

Funder: Technological Unversity Dublin 
Assessing the correlation of microscopy-based and volumetry-based measurements for resin swelling in a range of potential greener solvents for SPPS

Jordan Kevin Magtaan, ${ }^{\mathrm{a}}$ Marc Devocelle ${ }^{\mathrm{b}}$ and Fintan Kelleher ${ }^{\mathrm{a}^{*}}$

a Molecular Design \& Synthesis Group, Centre of Applied Science for Health, TU Dublin Tallaght, Dublin D24 FKT9, Ireland

${ }^{\mathrm{b}}$ Department of Chemistry, Royal College of Surgeons in Ireland, 123 St. Stephen's Green, Dublin 2, Ireland

Corresponding Author: Fintan Kelleher

Address: $\quad$ Centre of Applied Science for Health,

TU Dublin Tallaght,

Dublin D24 FKT9,

Ireland.

Phone Number:

(+353 1) 4042869

E-mail address: fintan.kelleher@tudublin.ie 


\section{Graphical abstract:}

Assessing the correlation of microscopy-based and volumetry-based measurements for resin swelling in a range of potential greener solvents for SPPS

Jordan Kevin Magtaan, Marc Devocelle and Fintan Kelleher ${ }^{\star}$

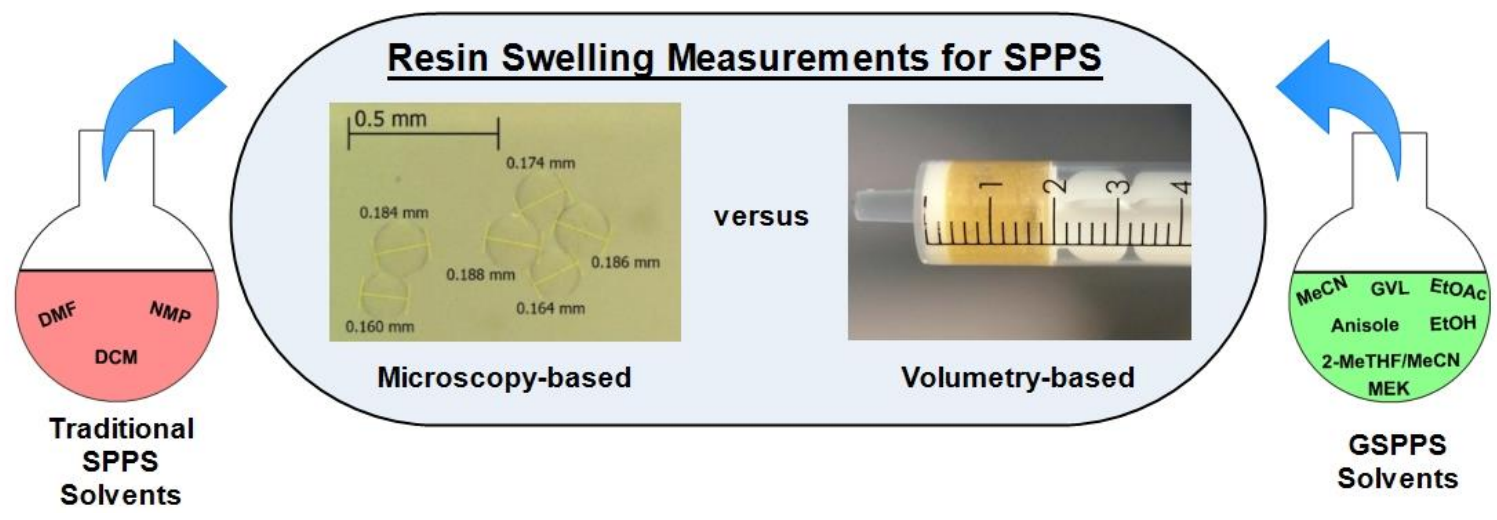




\title{
Assessing the correlation of microscopy-based and volumetry-based measurements for resin swelling in a range of potential greener solvents for SPPS
}

\author{
Jordan Kevin Magtaan, ${ }^{a}$ Marc Devocelle ${ }^{\mathrm{b}}$ and Fintan Kelleher ${ }^{\mathrm{a}^{*}}$
}

aMolecular Design \& Synthesis Group, Centre of Applied Science for Health, TU Dublin Tallaght, Dublin D24 FKT9, Ireland

Department of Chemistry, Royal College of Surgeons in Ireland, 123 St. Stephen's Green, Dublin 2, Ireland

\section{Abstract}

The degree of resin swelling in a particular solvent system is one of the critical parameters for SPPS, and for solid phase synthesis, in general. Methods used for measuring the degree of resin swelling include microscopy-based and volumetrybased methods. This study describes, and compares, the use of both methods for a number of commercially available resins commonly used in SPPS, with a range of solvents which have been identified in the literature as "greener" than DCM, DMF and NMP. The results were analysed by statistical methods and a significant correlation between the two distinct methods has been demonstrated for the first time. The results will likely be used, in conjunction with other literature methods, to help in choosing both the resin and solvent system for greener SPPS (GSPPS), as well as for continuous flow SPPS, which is of growing importance.

\section{Keywords}

Solid-phase peptide synthesis (SPPS); resin swelling; green chemistry; green solidphase peptide synthesis (GSPPS); continuous flow SPPS.

\section{Introduction}

R. B. Merrifield developed solid-phase peptide synthesis (SPPS) in the early 1960s and since then it has become the method of choice for the chemical synthesis of peptides. ${ }^{1,2}$ Two parameters that are critical to the successful, efficient synthesis of 
any peptide by SPPS are the choice of resin and solvent. In the vast majority of cases, DMF and NMP are the solvents of choice for SPPS, and the myriad of resins, coupling reagents, and amino acid protecting groups have been developed, and commercialised, were for use in these solvents. ${ }^{3-12}$ With growing concerns over their safety, environmental impacts and the imposition of restrictions by EU REACH regulations for these solvents, ${ }^{13}$ it is now imperative that 'greener' replacements are found. DCM, a solvent that is also generally regarded as problematic, is mainly used in SPPS during the washing and swelling steps. 5,14 Advances in green solid-phase peptide synthesis (GSPPS) have been recently reviewed by Albericio and by Sarojini. ${ }^{15,16}$

In parallel with the advances being made in the greening of SPPS, there are also strides being made in the use of continuous flow methodology, not just in small molecule pharmaceutical API synthesis, but now also in SPPS. ${ }^{17-21}$ Detailed knowledge of the resins in the normal peptide synthesis solvents, i.e. DMF, NMP and DCM, in continuous flow SPPS is therefore critical if this methodology is to become mainstream. Likewise, if this methodology is to be undertaken in conjunction with the greening efforts, then detailed studies of efficient functional properties of resins in "greener solvents" are required.

It has been known for decades that the degree of swelling of a resin in the solvent(s) being used for the synthesis, either by SPPS or by solid-phase organic synthesis (SPOS), is important for the successful outcome of the synthetic endeavour. ${ }^{22,23}$ When resins are treated with solvent, their volume generally increases (Figure 1) as regions between the cross-linked polymer chains within the resin beads are occupied by solvent molecules. Kent recently demonstrated the enhanced solvation of peptides, for example, of an elastin sequence, when attached to a swollen resin. ${ }^{24}$ Although the swelling behaviour of the many different types of commercially available resins are well known in DMF, NMP and DCM, less is known about their behaviour in some of the newer greener solvents, which are being proposed as replacements. Recently, Albericio, North and Lopez investigated the swelling behaviour of some resins in different greener solvents. ${ }^{25-27}$ In particular, North used the Hansen Solubility Parameters in Practice (HSPiP) software ${ }^{28}$ to be able to predict the swelling property of resins in a wide range of "green" solvents. 

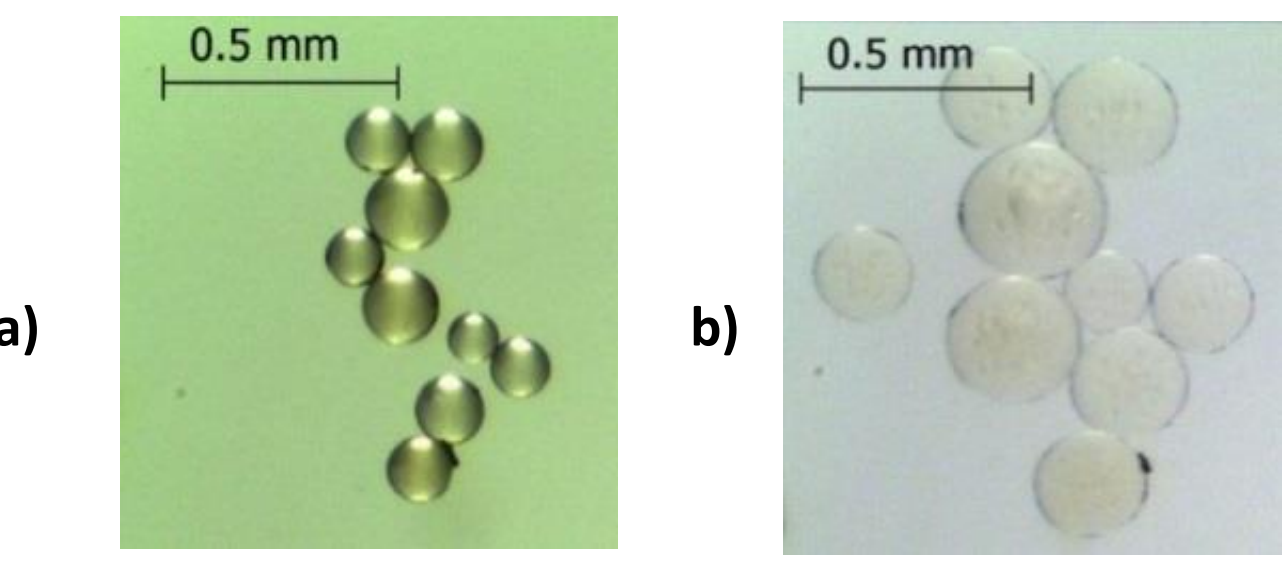

Figure 1. Light microscopy images showing (a) WangChemMatrix ${ }^{\circledR}$ resin prior to treatment with acetonitrile $(\mathrm{MeCN})$; and (b) the same resin when swollen.

The vast majority of reaction sites are found within the resin as opposed to on the surface. Therefore, greater resin swelling enhances access to these sites, while diminished access to reaction sites and abated reaction rates are consequences of inadequate resin swelling. ${ }^{23,29}$

Resin swelling can be determined in simple ways such as volumetric methods or an optical microscopy-based method. ${ }^{30}$ The first method involves simply measuring the resin's swollen volume, typically in $\mathrm{mL} . \mathrm{g}^{-1},{ }^{23,31}$ which is usually done in glass-fritted burettes or fritted SPPS reactors. However, while simple and fast, this method detects small differences in swelling with low accuracy. As an alternative, it is also possible to express resin swelling through the determination of the percentage of the bead volume occupied by the solvent, by calculating the swelling ratio (SR). ${ }^{32,33}$ Swelling ratio, in this context, is defined as the ratio of the swollen diameter of the resins to the untreated dry diameter of the resins, where the diameter measurements can be obtained using optical-microscopy. We undertook a study to compare these two methods, using a range of greener solvents, and also to ascertain whether there was any correlation ${ }^{34,35}$ between the results obtained from both methods.

\section{Results and Discussion}

All measurements were carried out in at least triplicate, as replicate measurements allows for the determination of the uncertainty of measurements, which provides an 
insight on the reliability, reproducibility and precision of the measurements. Statistical scatter was also measured using the percentage relative standard deviation (\%RSD), also referred to as the percentage coefficient of variation (\%CV). \%CV values of analytical measurements give an immediate indication of the precision of a measurement. For routine measurements in chemistry, \%CV values less than or equal to $5 \%$ are typical. ${ }^{36,37} \mathrm{~A}$ set of measurements with values of $\% \mathrm{CV}$ less than $1 \%$ are considered to be highly reproducible and precise. Normality tests that were used include the D'Agostino-Pearson Omnibus K2 test and the Shapiro-Wilk test. ${ }^{34}$

In order to cover a broad group, resins with two different cores and linkers were chosen. The resins selected were Merrifield, Sieber Amide, 2-chlorotrityl chloride (2CTC), Rink Amide 4-Methylbenzhydrylamine (Rink Amide MBHA; RA-MBHA) and Wang for the PS-based resins, and aminomethyl ChemMatrix ${ }^{\circledR}$ (AM-CM), ${ }^{38} \mathrm{H}$-Rink Amide-CM (H-RA-CM) and Wang-CM for the PEG-based resins.

Solvents contribute to a large bulk of the waste produced by the chemical/pharmaceutical industry. For instance, in an Irish context, according to an EPA report in 2010, about $96 \%$ of the solvent waste in Ireland is generated primarily by the Pharma-Chemical sector. ${ }^{39}$ Reducing the amount used and selecting the "greenest" solvent allows for the mitigation of the environmental impact of such processes. Solvents with improved EHS (environmental, health and safety) properties are also generally considered 'greener'. ${ }^{40,41}$ In fact, the fifth principle of green chemistry encourages the use of safer solvents and auxiliaries. ${ }^{42}$ In recent years a number of solvent selection guides ${ }^{43}$ have been reported for use in the chemical and pharmaceutical industries. The CHEM21 selection guide combines all of the data of these other selection guides giving overall recommendations. ${ }^{14,44}$ The solvent selection guides are structured around the EHS properties of solvents, and have been described in terms of a 'traffic light' system of solvent classification. In this system, solvents in the red zone (including DMF, NMP and DCM) should be avoided while those in the green zone should be used, where possible. The examples of solvents that have been identified as 'greener' than DMF, NMP and DCM, and included in this study are shown in Figure 2. 
Ethyl acetate (EtOAc)

Ethanol (EtOH)

2-Methyltetrahydrofuran (2-MeTHF)

Methyl ethyl ketone (MEK)
Acetonitrile $(\mathrm{MeCN})$

gamma-Valerolactone (GVL)

Anisole

$\mathbf{5 0} \%$ 2-MeTHF/Acetonitrile (v/v)

Figure 2. The 'Greener' solvents investigated in this study. The solvents listed above have been ranked as "green" or "yellow" in the CHEM21 solvent guide. ${ }^{45}$

Ethyl acetate and ethanol are recommended in the CHEM21 guide, as is anisole in the ether solvent category and methyl ethyl ketone (MEK, 2-butanone) in the ketone category. Albericio has reported the use of acetonitrile (MeCN), 2methyltetrahydrofuran (2-MeTHF) and gamma-valerolactone (GVL) as greener replacements for DMF and NMP in SPPS, and demonstrated that "difficult" peptides can be successfully synthesised when using the aforementioned greener solvents. ${ }^{15,25,46-48}$ We have also reported the use of GVL and another green solvent Cyrene $^{\mathrm{TM}}$ (dihydrolevoglucosenone) ${ }^{49}$ as part of our previous studies involving the critical initial loading stage of SPPS. ${ }^{50}$ Studies involving mixtures of greener solvent systems, in the context of GSPPS, have been applied by Schütznerová ${ }^{51}$, North, ${ }^{52}$ Rasmussen ${ }^{53}$ and Cabri ${ }^{54}$. Recently, North also reported highly detailed swelling and peptide synthesis study involving mixed solvent systems, including mixed green solvents..$^{52}$ North found that, in general, the swelling properties of Hypogel 200 and Merrifield resins in certain binary solvent systems do not vary linearly relative to the composition of the mixture. ${ }^{52}$ In this current study, the last solvent system chosen was a mixture of $50 \% 2-M e T H F / M e C N(v / v)$ to examine how this dual solvent mixture performed during resin swelling when compared to the performance of the individual solvent components. To the best of our knowledge, 50\% 2-MeTHF/MeCN $(\mathrm{v} / \mathrm{v})$ has not been proposed as a GSPPS solvent in the published literature. The solubility of some SPPS reagents in some of the greener solvent systems in Figure 2 has been investigated by Lopez. ${ }^{27}$ 


\section{Optical Microscopy-Based Studies of Resin Swelling}

The diameters $(\mu \mathrm{m})$ of randomly selected resin samples (polystyrene-based and PEG-based resins) when swollen for $10 \mathrm{~min}$ in DMF, NMP, DCM, and the greener alternative solvents, were measured $(n=125)$ and compared, as seen in Figure 3. For comparison, dry resins $(n=125)$ were sampled and the untreated dry diameters were also measured. Merrifield observed during studies of resins using microscopy, maximum swelling volume was attained within seconds when using non-viscous solvents, DCM and DMF, ${ }^{55}$ while Albericio used a 5 min period ${ }^{25}$ for resin swelling in studying 2-MeTHF and CPME for SPPS. For these reasons, it was deemed that 10 min was an adequate time for equilibrium to be reached.
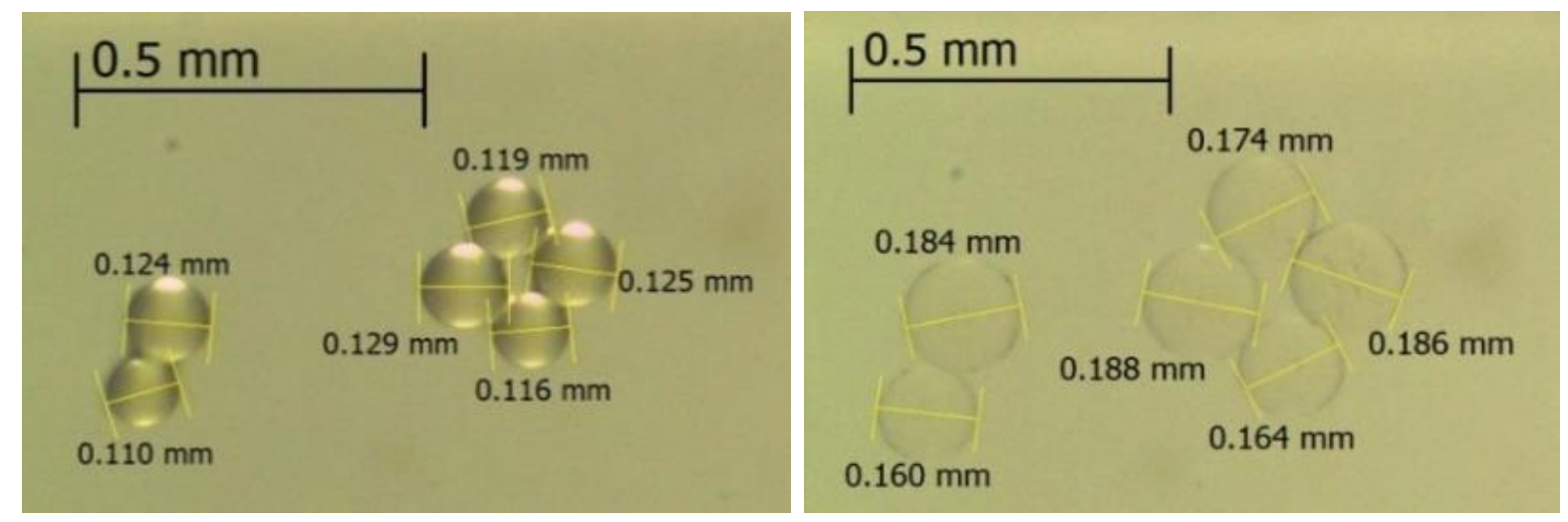

Figure 3: Representative images of the optical microscopy studies. Dry Wang-CM resins (left) and swollen Wang-CM resins in EtOAc after 10 min (right)

In a number of literature studies, resins were passed through a metal sieve in order to give a more uniform resin particle size. In our study, using conditions more representative of standard practice, the resins were used as received from the commercial suppliers.

Scatter was shown using histograms and \%CV calculations using the PRISM software (see supporting information for full set of histograms and summary statistics). For example, the histogram for MeCN in Figure 4 shows a high degree of data point spread, as also reflected by the high magnitude of the \%CV, which is greater than $5 \%$ in all cases. 


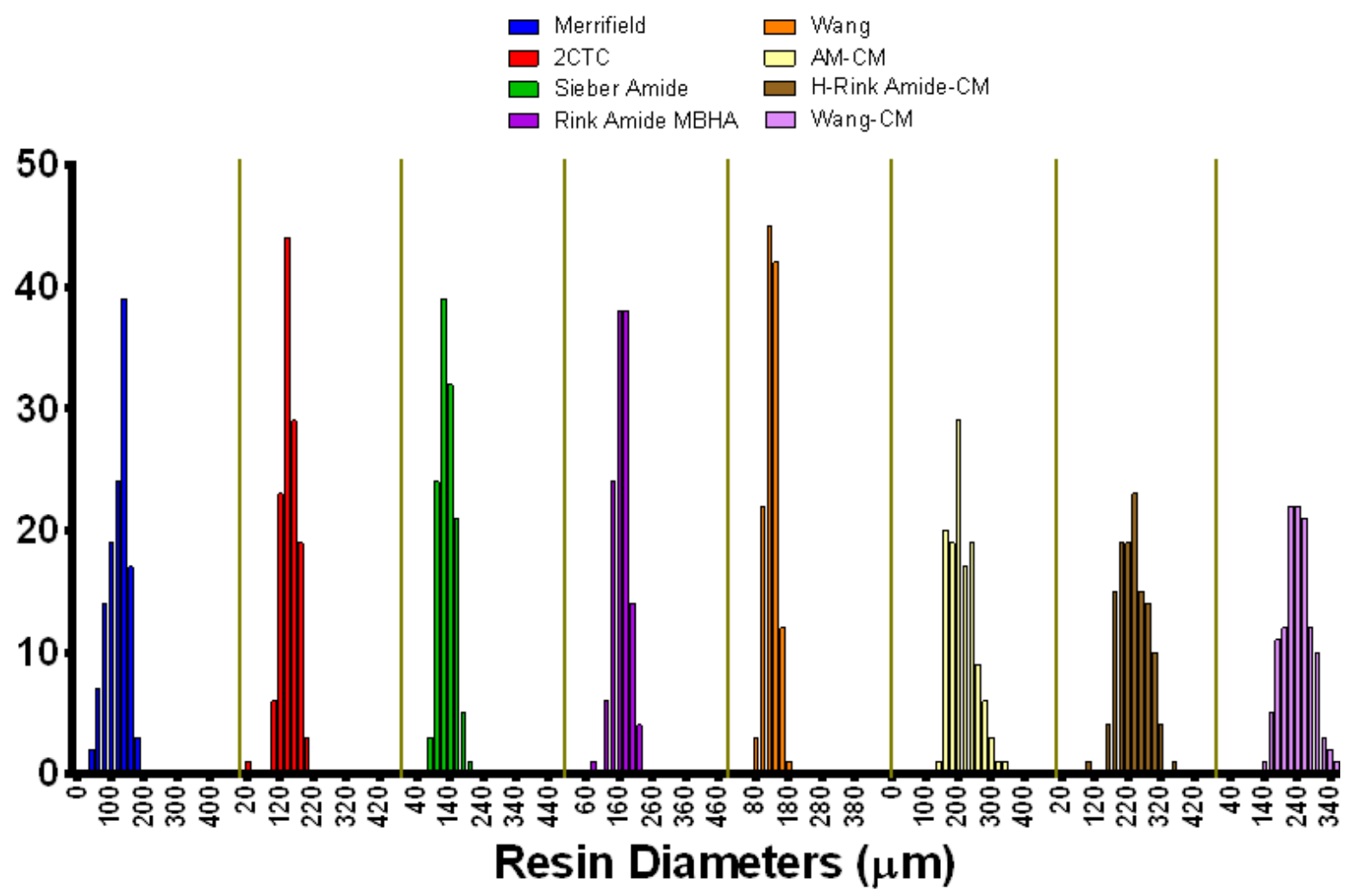

Figure 4: Representative histograms of the data from the optical microscopy studies involving $\mathrm{MeCN}$

It has been reported that polystyrene resin beads have a log-normal distribution and that the geometric mean is more accurate for describing resin diameters. ${ }^{55}$ However, in many cases during our studies, evidence for a normal distribution was observed during the D'Agostino-Pearson Omnibus K2 and Shapiro-Wilk normality tests. Also, as per the central limit theorem, distributions approach normality at larger sample sizes $(n>30) .{ }^{56}$ As such, we calculated the arithmetic means instead for expressing the central value of resin diameters and for calculating SR. The results of the optical microscopy measurements have been summarised in Table 1 and Figure 5. 
Table 1: Mean values for the resin diameter $(\mu \mathrm{m})$ measurements $(n=125)$. Superscripts denote that the data passed at least one of the normality tests, where $\dagger=$ D'Agostino-Pearson Omnibus K2 normality test and $\ddagger=$ Shapiro-Wilk normality test. First column: PS-based resins are highlighted in light purple and PEG-based resins are highlighted in light yellow. Red text $=$ traditional SPPS solvents, green text $=$ greener solvent systems and dark blue text $=$ resins .

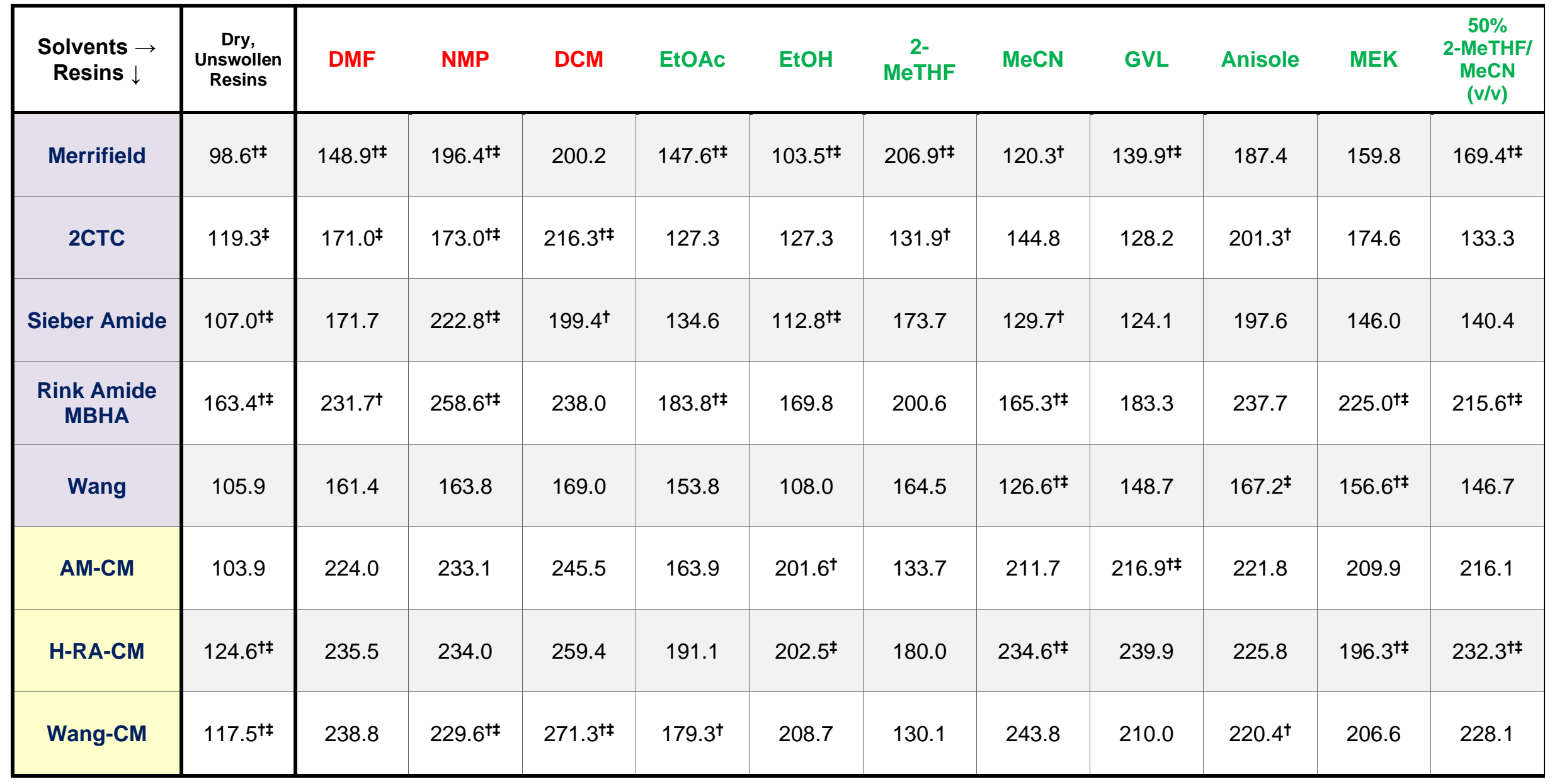




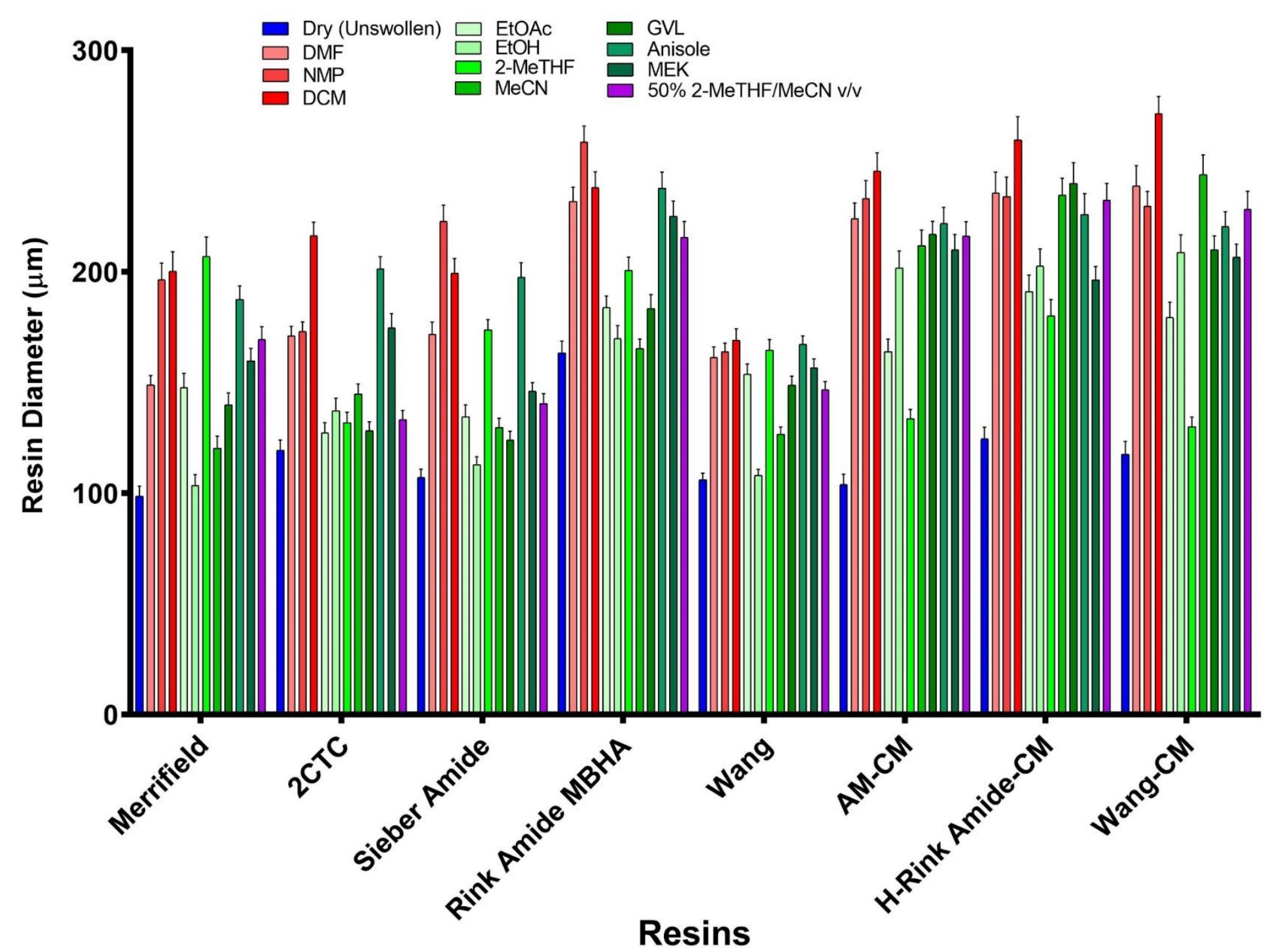

Figure 5: Bar chart of mean resin diameters $(n=125)$ of resins in different solvents. Error bars denote $95 \% \mathrm{Cl}$. Blue $=$ dry; shades of red $=$ traditional solvents; shades of green $=$ greener solvents (unary) and purple $=$ greener binary solvent. 
The swelling ratios (SR) were calculated, using the measured mean resin diameters, to express resin swelling (Equation 1).

$$
S R=\frac{\bar{x}_{s}}{\bar{x}_{d}}
$$

Equation 1: Equation for calculating swelling ratios ( $S R$, dimensionless), where subscript $s$ denotes swollen state and subscript $d$ denotes dry state. $\bar{x}$ denotes sample arithmetic mean resin diameters $(\mu \mathrm{m})$.

Swelling ratios greater than 1.0 indicate resin expansion upon treatment with solvent, with swelling values of 1.5 indicating an increase in mean resin diameter of $50 \%$. High SR values are desirable. 
Table 2: Calculated swelling ratio (SR, dimensionless) values. First column: PS-based resins are highlighted in light purple and PEG-

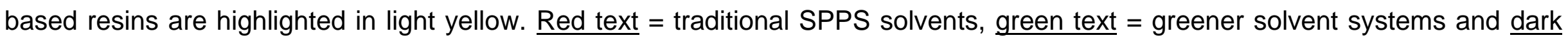
$\underline{\text { blue text }}=$ resins.

\begin{tabular}{|c|c|c|c|c|c|c|c|c|c|c|c|}
\hline $\begin{array}{l}\text { Solvents } \rightarrow \\
\quad \text { Resins } \downarrow\end{array}$ & DMF & NMP & DCM & EtOAc & EtOH & $\stackrel{2-}{\text { MeTHF }}$ & $\mathrm{MeCN}$ & GVL & Anisole & MEK & $\begin{array}{c}50 \% \\
2- \\
\text { MeTHF/ } \\
\text { MeCN } \\
\text { (v/v) } \\
\end{array}$ \\
\hline Merrifield & 1.51 & 1.99 & 2.03 & 1.50 & 1.05 & 2.10 & 1.22 & 1.42 & 1.90 & 1.62 & 1.72 \\
\hline 2CTC & 1.43 & 1.45 & 1.81 & 1.07 & 1.15 & 1.11 & 1.21 & 1.07 & 1.69 & 1.46 & 1.12 \\
\hline Sieber Amide & 1.60 & 2.08 & 1.86 & 1.26 & 1.05 & 1.62 & 1.21 & 1.16 & 1.85 & 1.36 & 1.31 \\
\hline $\begin{array}{c}\text { Rink Amide } \\
\text { MBHA }\end{array}$ & 1.42 & 1.58 & 1.46 & 1.12 & 1.04 & 1.23 & 1.01 & 1.12 & 1.45 & 1.38 & 1.32 \\
\hline Wang & 1.52 & 1.55 & 1.60 & 1.45 & 1.02 & 1.55 & 1.20 & 1.40 & 1.58 & 1.48 & 1.39 \\
\hline H-RA-CM & 1.89 & 1.88 & 2.08 & 1.53 & 1.63 & 1.44 & 1.88 & 1.93 & 1.81 & 1.58 & 1.86 \\
\hline Wang-CM & 2.03 & 1.95 & 2.31 & 1.53 & 1.78 & 1.11 & 2.07 & 1.79 & 1.88 & 1.76 & 1.94 \\
\hline
\end{tabular}


In most cases, for both the PS and PEG-based resins, the mean resin diameters were highest when the resins were treated with the traditional SPPS solvents DMF, NMP and DCM. Overall, the SR values were highest in DCM. One exception is the high mean resin diameter of Merrifield resins when treated with 2-MeTHF (Figure 5 \& Table 2). Another exception was the determined mean resin diameters in anisole, which were similar to the values of the traditional solvents. In polar solvent systems, particularly for $\mathrm{EtOH}$ and $\mathrm{MeCN}$, it was observed that the diameters of PS-based resins do not increase much compared to when treated with less polar solvents such as 2-MeTHF ( $S R<1.5)$. The case of low increases in mean diameters is also reflected by the calculated SR values which are close to one (Table 2). Resin diameters for 2-CTC resins are generally low in the greener solvents, with the exception of anisole and MEK.

In contrast, $\mathrm{SR}$ values of $>1.5$ indicate that in $\mathrm{EtOH}$ and $\mathrm{MeCN}$, the mean resin diameters increased by more than $50 \%$, compared to when the resins were in the dry state. On the other hand, SR values for the CM resins were low in 2-MeTHF. Overall, the SR values for the CM resins, when treated with greener solvent systems, were comparable to the SR values when CM resins were treated with traditional SPPS solvents, with SR values and mean resin diameters being highest in DCM.

In resin swelling, the use of the $50 \%$ 2-MeTHF/MeCN (v/v) binary solvent mixture generally resulted in SR values that mostly lie between the calculated values of the individual constituent solvents. However, the Rink Amide MBHA and AM-CM resins showed higher SR than either of the individual solvents. It was also noted that the use of this binary solvent system resulted in an improvement in the swelling profile for CM resins, compared to when 2-MeTHF alone was used. However, the 2-CTC resin was determined to have low swelling, even in the binary solvent system.

\section{Determination of Resin Swelling by Volumetric Analysis}

Volumetric analysis is the most common way of quantitating resin swelling. In this study, the method of Griffith, independently implemented by Lawrenson, was selected. ${ }^{23,26}$ In line with the $1^{\text {st }}$ principle of green chemistry, the resins were reused for swelling measurements using a similar washing procedure to that of Bradley. ${ }^{57}$ 
The measurements were performed in graded $5 \mathrm{ml}$ polyphenylene ether-fritted (PPE-fritted) syringes, while accounting for the frit volume in the calculations.

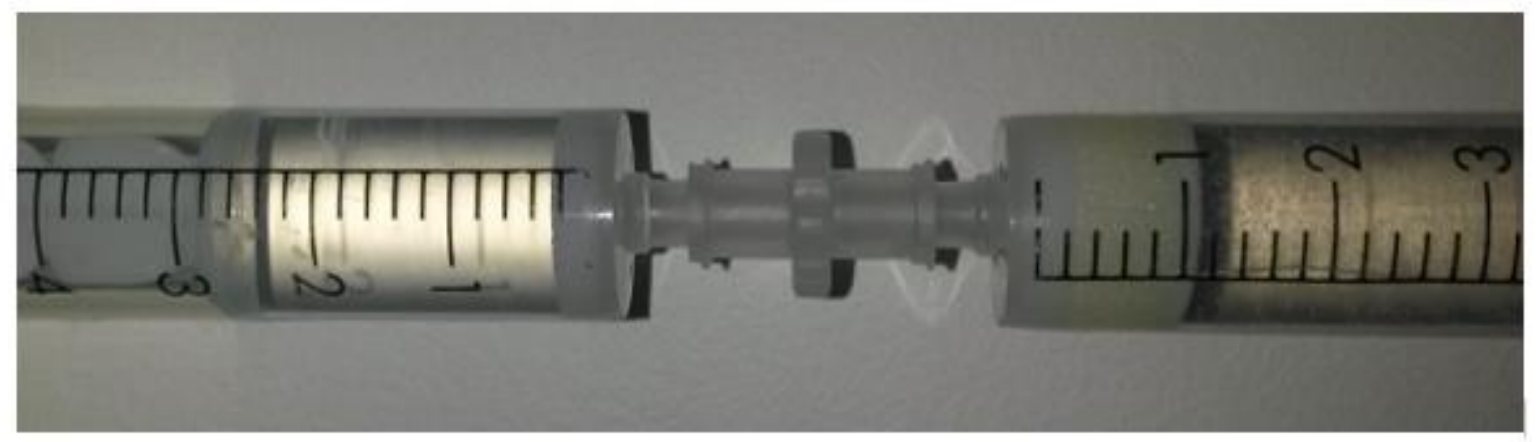

Figure 6 Image of the equipment used for the swelling studies, based on the method of Griffith. ${ }^{23}$ (See Materials and Methods for the experimental details).

The volume $\left(\mathrm{V}_{\mathrm{F}}\right)$ of the rigid cylindrical frit (quintuplicate, $\mathrm{n}=5$ ) obtained from different syringes was determined from measurements obtained using a micrometer screw gauge. The mean frit volume was found to have little variation and was calculated to be $0.352 \pm 0.0098(0.0069) \mathrm{cm}^{3}$, where 0.352 is the sample mean, 0.0098 is the $95 \% \mathrm{Cl}$ and $(0.0069)$ is the sample standard deviation. As shown by the low value for the standard deviation and a low \%CV $(<5 \%)$, the dispersion is low. Hence, this mean value was taken as the volume of the frit for all volumetry-based resin swelling calculations, see Table 3

Table 3: Calculation of the volume of dry PPE frits $(n=5)$, from frit dimensions where $\mathrm{d}=$ diameter $(\mathrm{cm}), r=$ radius $(\mathrm{cm}), \mathrm{h}=$ height $(\mathrm{cm})$, and $\mathrm{V}=$ volume $\left(\mathrm{cm}^{3}\right)$, which is determined using $V=\pi r^{2} h$.

\begin{tabular}{|ccccc|}
\hline $\begin{array}{c}\mathbf{n}^{\text {th }} \\
\text { measurement }\end{array}$ & $\begin{array}{c}\mathbf{d} \\
(\mathbf{c m})\end{array}$ & $\begin{array}{c}\mathbf{r} \\
(\mathbf{c m})\end{array}$ & $\begin{array}{c}\mathbf{h} \\
(\mathbf{c m})\end{array}$ & $\begin{array}{c}\mathbf{V} \\
\left(\mathbf{c m}^{\mathbf{3}}\right)\end{array}$ \\
\hline $\mathbf{1}$ & 1.210 & 0.605 & 0.309 & 0.355 \\
\hline $\mathbf{2}$ & 1.214 & 0.607 & 0.306 & 0.354 \\
\hline $\mathbf{3}$ & 1.195 & 0.598 & 0.305 & 0.342 \\
\hline $\mathbf{4}$ & 1.203 & 0.602 & 0.306 & 0.348 \\
\hline $\mathbf{5}$ & 1.208 & 0.604 & 0.314 & 0.360 \\
\hline
\end{tabular}

Solvents that give resin swelling values $\geq 4.0 \mathrm{~mL} \cdot \mathrm{g}^{-1}$ are regarded as good solvents, $2.0-4.0 \mathrm{~mL} . \mathrm{g}^{-1}$ is moderate, and $<2.0 \mathrm{~mL} . \mathrm{g}^{-1}$ is deemed poor and their use is discouraged. ${ }^{23}$ In our study, using Griffith's method, measurements were performed 
in replicate using a small sample size (triplicate, $n=3$ ), due to the high cost associated with using large quantities of resins. Resin swelling was calculated using the formula shown in Equation 2, while Figure 7 and Table 4 shows the results obtained.

$$
S=\frac{V_{T}-V_{F}}{m}
$$

Equation 2: The equation for calculating swelling ratios $\left(\mathrm{mL} \cdot \mathrm{g}^{-1}\right)$ using volumetric methods. $V_{T}=$ total volume $(\mathrm{mL}), V_{F}=$ frit volume $(\mathrm{mL})$ and $m=$ mass of the resins (g) 


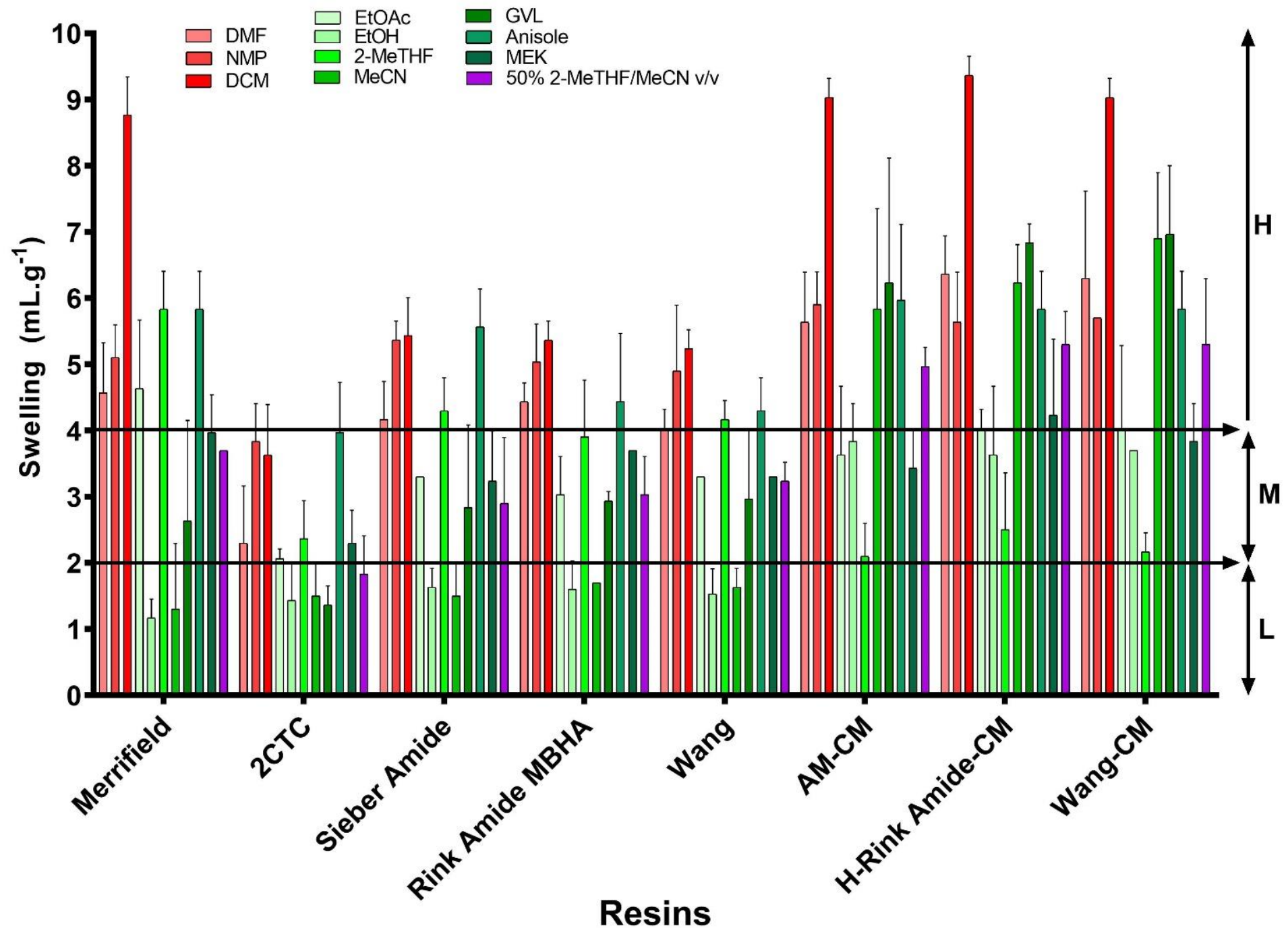

Figure 7: Bar chart comparing volumetry-based resin swelling measurements ( $\mathrm{mL} \cdot \mathrm{g}^{-1} ; \mathrm{n}=3$ ) of resins in different solvents. Error bars denote $95 \% \mathrm{Cl}$. Blue = dry; shades of red = traditional solvents; shades of green = greener solvents (unary) and purple = greener binary solvent. $H, M$ and $L$ stand for high, moderate and low swelling, respectively. 
Table 4: Mean values for the resin swelling $\left(\mathrm{mL} \cdot \mathrm{g}^{-1}\right)$ measurements $(\mathrm{n}=3)$. In dark blue: Resins. In red: traditional SPPS solvents. In green: Possible greener alternatives. $\mathrm{H}, \mathrm{M}$ and $\mathrm{L}$ stand for high, moderate and low swelling, respectively. \%CV was $6.4 \%$, on average.

\begin{tabular}{|c|c|c|c|c|c|c|c|c|c|c|c|}
\hline Resins & DMF & NMP & DCM & EtOAc & EtOH & $\stackrel{2-}{\text { MeTHF }}$ & $\mathrm{MeCN}$ & GVL & Anisole & MEK & $\begin{array}{c}50 \% \\
2- \\
\text { MeTHF/ } \\
\text { MeCN } \\
\text { (v/v) } \\
\end{array}$ \\
\hline Merrifield & $4.9^{H}$ & $4.9^{\mathrm{H}}$ & $8.9^{H}$ & $4.3^{\mathrm{H}}$ & $1.1^{\mathrm{L}}$ & $6.1^{\mathrm{H}}$ & $1.3^{\mathrm{L}}$ & $2.5^{\mathrm{M}}$ & $5.7^{\mathrm{H}}$ & $3.7^{\mathrm{M}}$ & $3.7^{\mathrm{M}}$ \\
\hline 2CTC & $1.9^{L}$ & $4.1^{\mathrm{H}}$ & $3.9^{\mathrm{M}}$ & $2.0^{\mathrm{M}}$ & $1.3^{\mathrm{L}}$ & $2.1^{\mathrm{M}}$ & $1.5^{\mathrm{L}}$ & $1.3^{\mathrm{L}}$ & $4.3^{H}$ & $2.3^{\mathrm{M}}$ & $1.8^{\mathrm{L}}$ \\
\hline RA-MBHA & $4.5^{\mathrm{H}}$ & $5.3^{\mathrm{H}}$ & $5.5^{\mathrm{H}}$ & $2.9^{M}$ & $1.4^{\mathrm{L}}$ & $3.7^{\mathrm{M}}$ & $1.7^{\mathrm{L}}$ & $3.0^{\mathrm{M}}$ & $4.9^{\mathrm{H}}$ & $3.7^{\mathrm{M}}$ & $3.0^{\mathrm{M}}$ \\
\hline Wang & $4.1^{\mathrm{H}}$ & $5.3^{\mathrm{H}}$ & $5.1^{\mathrm{H}}$ & $3.3^{\mathrm{M}}$ & $1.4^{\mathrm{L}}$ & $4.3^{\mathrm{H}}$ & $1.7^{\mathrm{L}}$ & $3.1^{\mathrm{M}}$ & $4.3^{\mathrm{H}}$ & $3.3^{\mathrm{M}}$ & $3.2^{\mathrm{M}}$ \\
\hline Wang-CM & $5.7^{\mathrm{H}}$ & $5.7^{\mathrm{H}}$ & $9.1^{\mathrm{H}}$ & $3.5^{\mathrm{M}}$ & $3.7^{\mathrm{M}}$ & $2.3^{\mathrm{M}}$ & $6.5^{\mathrm{H}}$ & $7.1^{\mathrm{H}}$ & $5.7^{\mathrm{H}}$ & $4.1^{\mathrm{H}}$ & $5.3^{\mathrm{H}}$ \\
\hline
\end{tabular}


For analytical measurements, it is recommended to have a sample size of at least 5 to 8 . The effect of having a small sample size is evident in the larger magnitude of the $\mathrm{Cl}$ \%CV values for the resin swelling measurements by volumetric measurements averaged at $6.4 \%$, which exceeds the $\leq 5 \% \% \mathrm{CV}$ that is typical of routine analytical measurement. ${ }^{36}$

It can be seen from Figure 7 and Table 4 that for both PS-based and PEG-based resins, swelling in the traditional solvents - DMF, NMP and DCM - was generally highest, which is in agreement with swelling studies carried out in the literature. Nonpolar and moderately polar solvents tend to swell PS-based resins well. However, as shown here, DMF and NMP, which are relatively more polar than many of the solvents used in the investigation, are exceptions. Out of all the solvents investigated, that are ranked greener than DMF, NMP and DCM in solvent selection guides, anisole is the only greener solvent with a highly similar swelling profile. Overall, 2-MeTHF and anisole have similar and, in some instances, greater swelling of PS-based resins when compared to DMF, NMP, and DCM. Similarly to the optical microscopy data, 2-CTC resins, in most cases, have low or moderate swelling, even in the traditional solvents used in SPPS. Both EtOAc and 2-MeTHF gave moderate to high swelling for the PS-based resins. In contrast, swelling values of PS-based resins in $\mathrm{EtOH}$ and $\mathrm{MeCN}$ are low, i.e., less than $2.0 \mathrm{~mL} . \mathrm{g}^{-1}$. MEK, a ketone ranked green by the CHEM21 solvent selection guide, was shown to give moderate swelling for PS-based resins.

For the binary solvent system 50\% 2-MeTHF/MeCN (v/v), the measured mean swelling values are within the moderate range, with the exception of 2-CTC resins. In agreement with the literature and the data presented in the previous section, the PEG-based CM resins have high swelling in DCM. It was observed that the magnitude of mean swelling of the 2-CTC resins ranged from low to moderate, except in NMP and anisole, where the swelling is greater than $4.0 \mathrm{~mL}^{-1}{ }^{-1}$. With regard to the PEG-based resins, both DMF and NMP surpass 2-MeTHF, but not anisole. The swelling profile of anisole for the CM resins is very similar to that of DMF and NMP. For both MEK and 2- MeTHF, mean resin swelling values for the CM resins lie in the moderate region. 
In contrast to the swelling of PS-based resins, both $\mathrm{EtOH}$ and MeCN have better swelling profiles for PEG-based resins. For $\mathrm{EtOH}$, the mean swelling values of the three PEG-based resins are in the moderate range, while for both MeCN and GVL, values for the PEG-based resins are within the high range and are very similar to the values for DMF and NMP. It was noted that the use of binary solvent systems $50 \%$ 2-MeTHF/MeCN ( $v / v)$ gave swelling values within the high region for the PEG-based resins.

In order to ascertain which green solvent system gave the best overall swelling profile by volumetric measurements, a shading matrix was constructed to visualise the number of the analysed resin types within the high, moderate and low swelling regions in the greener solvents (Figure 8).
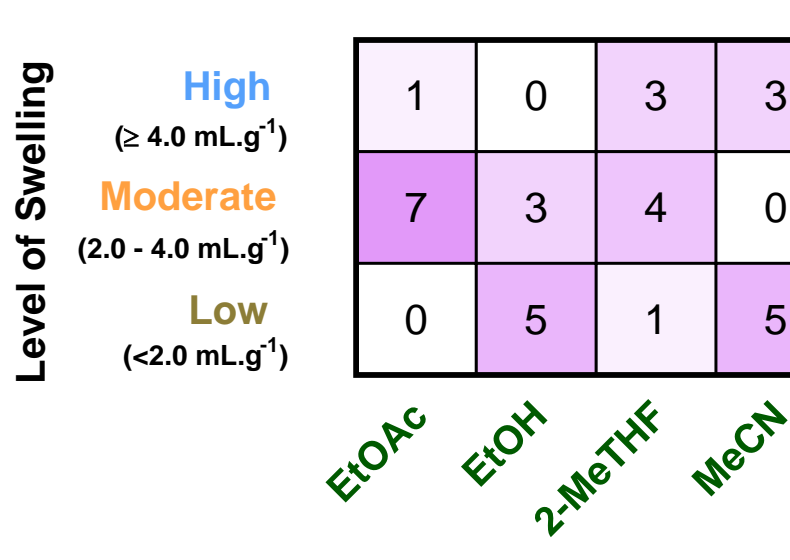

\section{Solvents}

Figure 8: Shading matrix showing the number of resin types at high, moderate and low swelling in different greener solvent systems.

Based on the shading matrix and previous data presented, anisole is the greener solvent system with the best swelling profile. After anisole, GVL, 2-MeTHF and the binary solvent system also had the highest number of resin types in the High swelling category $(H=3)$. The proposed greener alternative solvent for SPPS that gave the worst swelling profile, for the 8 resin types studied, was $\mathrm{EtOH}$, with no resins in the high region. 


\section{Assessment of the relationship between microscopy-based measurements and volumetry-based measurements for resin swelling}

Table 5: Interpretation of the correlation coefficient $(\mathrm{R}){ }^{45}$

\begin{tabular}{|c|c|}
\hline $\begin{array}{l}\text { Correlation Coefficient } \\
\text { (R) }\end{array}$ & Interpretation \\
\hline+1.0 & Perfect positive correlation \\
\hline 0.0 to +1.0 & $\begin{array}{c}\text { Variables tend to increase or decrease } \\
\text { together }\end{array}$ \\
\hline 0.0 & No correlation \\
\hline-1.0 to 0.0 & $\begin{array}{l}\text { As one variable increases, the other } \\
\text { decreases }\end{array}$ \\
\hline-1.0 & Perfect inverse correlation \\
\hline
\end{tabular}

To establish a mathematical relationship between SRs and S, the statistical Pearson correlation coefficient $(R)$ of the data between optical microscopy-based resin swelling measurements and volumetry-based resin swelling measurements was calculated (at significance $\alpha=0.05$ ), with PRISM software. ${ }^{34}$ Although both are methods of assessing resin swelling, a clear relationship between these two methods has not been established in the literature to date. $\mathrm{R}$, which can have a negative value, unlike the coefficient of regression $\left(R^{2}\right)$, is a mathematical measure of the strength and direction of the relationship between two variables. ${ }^{58-60}$ Values of $\mathrm{R}$ can range between -1 to +1 (Table 5 ), with values greater than +0.7 or lower than 0.7 generally regarded as demonstrating strong correlation. ${ }^{61} \mathrm{It}$ is important to mention that correlation is not indicative of a causal relationship. ${ }^{35}$ 
SR vs. S

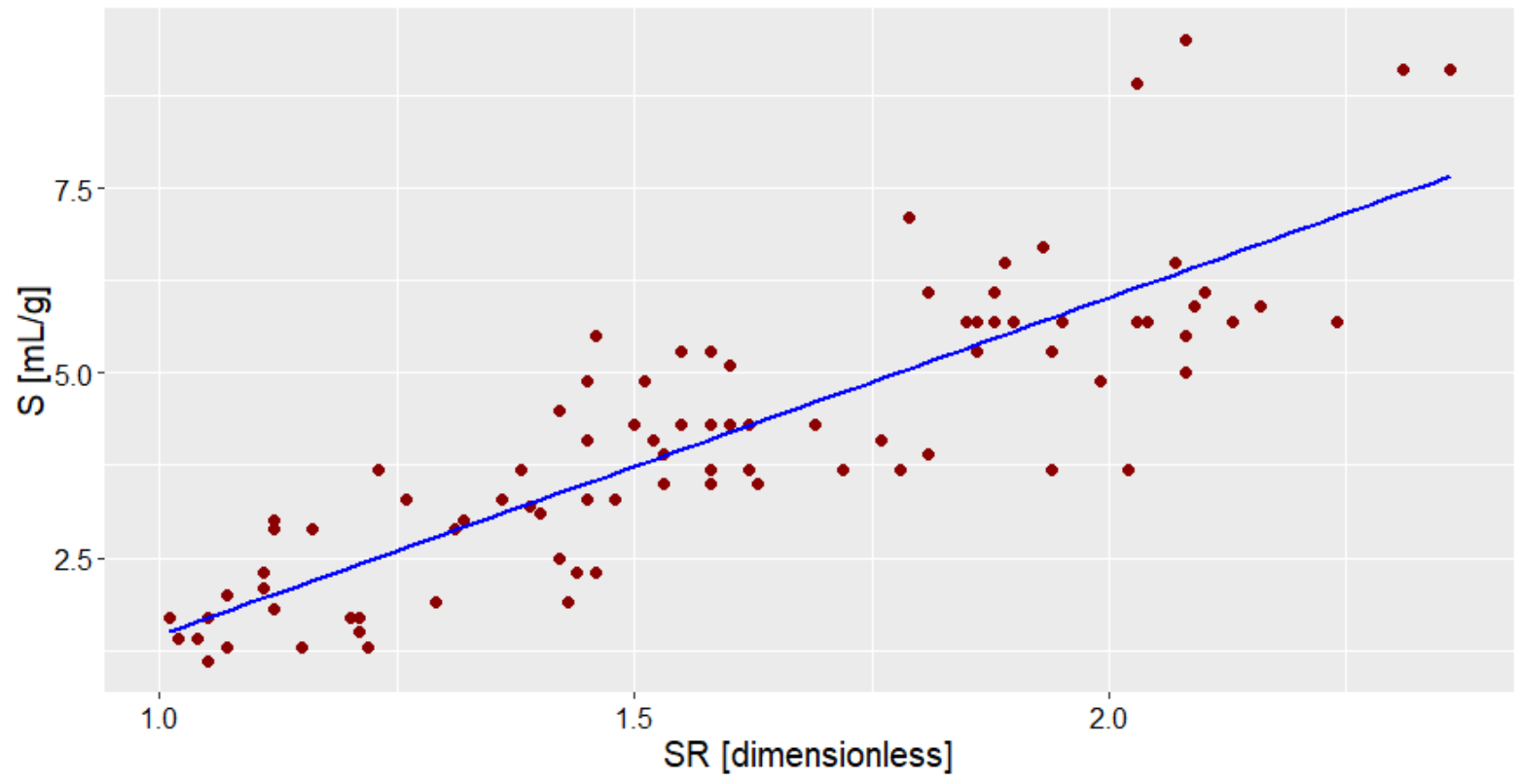

Figure 9: Visualisation (ggplot2) of the relationship between $S R$ and $S(n=88)$

Although correlation does not fit a line through the data points, ${ }^{59}$ a plot showing SR versus $S$ was generated for visualisation purposes (Figure 9), which shows many of the points close to the line $(R=1)$. The $R$ value for $S R$ and swelling $\left(m L \cdot g^{-1}\right)$ values $(\alpha=0.05)$ was determined $(n=88)$ and it was found that $R=+0.8542(p<0.05)$. Since a high positive value $(R>0.7)$ for $R$ was obtained, it indicates that the two variables have a tendency to increase or decrease together and that there is a reasonably strong positive correlation between the swelling results obtained using an optical microscopy-based method and a volumetry-based method.

Table 6: Key results of the correlation coefficient calculation using the PRISM software; $\mathrm{n}=88$.

\begin{tabular}{|cc|}
\hline Pearson Coefficient (R) summary & Result \\
\hline $\mathbf{R}$ & $\mathbf{+ 0 . 8 5 4 2}$ \\
\hline$p$-value summary & Result \\
\hline$p$ (two-tailed) & $<0.0001$ \\
$p$-value summary & ${ }_{\star \star \star \star}$ \\
Significant? $(\alpha=0.05)$ & Yes \\
\hline
\end{tabular}




\section{Conclusions}

Within the last decade, the interest in applying the principles of green chemistry to SPPS, now termed GSPPS, for all key stages of the technique, has increased. The studies presented herein focused on the important swelling step of SPPS when using greener solvents, which was quantified by two methods, namely by microscopy and volumetry. During our studies on the highly critical swelling step of SPPS, it was found that, in general, the traditional SPPS solvents (DMF, NMP and DCM) had the highest SR values, with DCM giving the highest resin diameter and SRs of resins overall. Anisole, a solvent ranked greener than DCM, DMF and NMP in the CHEM21 guide, was identified to give high SRs overall. The use of the binary solvent system $50 \%$ 2-MeTHF/MeCN ( $/ v$ ) has not been described as a possible replacement for traditional SPPS solvents in the published literature, to the best of our knowledge. Its use resulted in higher SR values in some cases compared to when the individual constituent solvents were used. As expected, it was found that the traditional solvents used for SPPS have the highest swelling values overall. Similar to the results obtained during the optical microscopy studies, the traditional solvents used for SPPS gave the highest resin swelling values overall. Anisole was identified again as one with a good swelling profile and may be a suitable replacement for the solvents traditionally used in SPPS during the swelling step. The results from these studies may also inform the design of resin reactor beds for continuous flow SPPS, and indeed for solid-phase organic synthesis (SPOS) methodologies. Based on the value of the Pearson correlation coefficient obtained $(R=+0.8542)$, a strong mathematical relationship between the microscopy and volumetry methods of measuring resin swelling $(\mathrm{R}>+0.7, p<0.05, \mathrm{n}=88$ ) was found. The study presented here focused on the important swelling step of SPPS, but we are undertaking studies on the use of greener solvents, including binary solvent systems, in the other steps of SPPS, and the results from these studies will be reported in due course.

\section{Materials and Methods}

The methods for determining swelling $\left(\mathrm{mL} \cdot \mathrm{g}^{-1}\right)$ and swelling ratios are based on previously described methods. ${ }^{23}$ Fritted PP-reactors $(25 \mu \mathrm{m}$ pore size, item 
V050PE063) were acquired from MultiSynTech GmbH (Germany). The reactors were agitated using a Vortex-Genie® Mixer. The resins were purchased from SigmaAldrich Ireland (all ChemMatrix resins), Iris Biotech $\mathrm{GmbH}$ (2CTC resins) or were provided by IPSEN Manufacturing Ireland Ltd (all other resins). Solvents were purchased from VWR, Sigma-Aldrich, and Acros Organics. Solvents used, except for GVL, EtOAc and 2-MeTHF, were of HPLC grade. 2-MeTHF was BHT stabilised (150-400 ppm) and absolute ethanol was used. The method for determining swelling ratios is based on a published method. ${ }^{62}$ Optical microscopy images were obtained using an Educational Stereo Microscope Leica EZ4 HD (35x magnification, $1600 \times 1200 \mathrm{px}, 1 \mathrm{px}=2 \mu \mathrm{m}$ ) and images were processed using Leica LAS EZ 3.0 software. Statistical analyses and data visualisation were performed using Microsoft Excel, GraphPad PRISM 7 and code written in the R programming language on RStudio with ggplot2.

\section{Volumetric Method of Measuring Resin Swelling in $\mathrm{mL}^{-g^{-1}}$}

Dry resin $(500 \mathrm{mg}$ ) was added to a graduated $5 \mathrm{~mL}$ syringe fitted with a PPE frit of known volume, calculated as the volume of a cylinder. The solvent $(5 \mathrm{~mL})$ was added to the syringe and the syringe was vortexed for $30 \mathrm{sec}$, left to stand for $1 \mathrm{~h}$ to ensure full swelling, and vortexed again for $30 \mathrm{sec}$. Excess solvent was removed using another syringe via a Luer-lok connector (see Figure 6). The volume of the swollen beads was recorded in triplicate $(n=3)$ and the swelling was calculated (in $\left.\mathrm{mL} . \mathrm{g}^{-1}\right)$. The solvent was removed and the resins were washed with $\mathrm{MeOH}(3 \times 5 \mathrm{~mL})$ and the next test solvent ( $3 \times 5 \mathrm{~mL}$, similar to the method of Bradley $)^{57}$ for the replicate measurements of resin swelling. 23,57

\section{Optical Microscopy Measurements of Resin Diameters}

Dry resins $(1-2 \mathrm{mg})$ were placed on a dry glass slide and treated with a small amount of solvent $(<2 \mathrm{~mL})$. The resins were allowed to be exposed to the solvent for $10 \mathrm{~min}$ and were occasionally agitated to ensure proper swelling. If required, additional solvent was added to prevent drying of the resins. The diameters of randomly selected resin beads $(n=125)$ were measured manually using the LAS EZ 3.0 software $^{63}$ and an optical microscope. Swelling ratios (SR) were determined, to 
express the resin bead volume change from the non-swollen state to the swollen state. 62

\section{Acknowledgements}

We would like to thank IPSEN Manufacturing Ireland Ltd. for very helpful discussions and supplying some of the resins for this study. Financial assistance for JKM is acknowledged from the IT Tallaght 2014 and 2016 President's Research Award programmes. We would also like to thank John Jones for his assistance during the optical microscopy studies.

\section{ORCID}

Jordan Kevin Magtaan ～https://orcid.org/0000-0001-5764-8455

Marc Devocelle $\quad$ https://orcid.org/0000-0001-7641-1306

Fintan Kelleher $\quad$ https://orcid.org/0000-0001-5507-9092

\section{Conflict of interest:}

The authors declare no conflict of interest.

\section{References}

1. Merrifield RB. Solid Phase Peptide Synthesis. I. The Synthesis of a Tetrapeptide. J Am Chem Soc 1963;85(14):2149-2154, DOI: 10.1021/ja00897a025.

2. Merrifield B. The Role of the Support in Solid Phace Peptide Synthesis. $\mathrm{Br}$ Polym J 1984;16(December):173-178, DOI: 10.1002/pi.4980160404.

3. Amblard M, Fehrentz J-A, Jean M, Subra G. Methods in Molecular Biology: Peptide Synthesis and Applications, Vol. 298. 2005, DOI: 10.1385/MB:33:3:239.

4. Forns P, Fields GB. The Solid Support. In Solid-Phase Synthesis: A Practical Guide, Kates SA, Albericio F (eds). Marcel Dekker Inc.: New York, NY, USA, $2000 ; 1-78$. 
5. Springer Protocols. Methods in Molecular Biology 1047: Peptide Synthesis and Applications, Jensen KJ, Shelton PT, Pedersen SL (eds), 2nd ed. Springer Science + Business Media: New York, NY, USA, 2013.

6. Coin I, Beyermann M, Bienert M. Solid-Phase Peptide Synthesis: From Standard Procedures to the Synthesis of Difficult Sequences. Nat Protoc 2007;2(12):3247-3256, DOI: 10.1038/nprot.2007.454.

7. van Regenmortel MH V, Muller JPBS, Plaué S. Chapter 2 Solid-Phase Peptide Synthesis. In Laboratory Techniques in Biochemistry and Molecular Biology, Vol. 19, Burdon $\mathrm{RH}$, van Knippenberg PH (eds). Elsevier Science Publishers B.V. (Biomedical Division): Amsterdam, The Netherlands, 1988; 41-94, DOI: 10.1016/S0075-7535(08)70006-8.

8. Bodanszky M. Principles of Peptide Synthesis, 2nd Edition. Springer-Verlag Berlin Heidelberg: Hong Kong, CN, 1993.

9. Fmoc Solid Phase Peptide Synthesis. A Practical Approach., Chan WC, White PD (eds). Oxford University Press: New York, NY, USA, 2000.

10. El-Faham A, Albericio F. Peptide Coupling Reagents, More than a Letter Soup. Chem Rev 2011;111:6557-6602, DOI: 10.1021/cr100048w.

11. Tickler AK, Wade JD. Overview of Solid Phase Synthesis of "Difficult Peptide" Sequences. Curr Protoc Protein Sci 2007;(November):Supplement 50: 18.8.118.8.6, DOI: 10.1002/0471140864.ps1808s50.

12. Behrendt R, White $P$, Offer J. Advances in Fmoc Solid-Phase Peptide Synthesis. J Pept Sci 2016;22(1):4-27, DOI: 10.1002/psc.2836.

13. Bergkamp L, Herbatschek N. Regulating Chemical Substances under REACH: The Choice between Authorization and Restriction and the Case of Dipolar Aprotic Solvents. Rev Eur Comp Int Environ Law 2014;23(2):221-245, DOI: 10.1111/reel.12083.

14. Prat D, Wells A, Hayler J, Sneddon HF, McElroy CR, Abou-Shehada S, Dunn PJ. CHEM21 Selection Guide of Classical - and Less Classical - Solvents. Green Chem 2016;18:288-296, DOI: 10.1039/C5GC01008J.

15. Jad YE, Kumar A, El-Faham A, de la Torre BG, Albericio F. Green Transformation of Solid-Phase Peptide Synthesis. ACS Sustain Chem Eng 2019;7(4):3671-3683, DOI: 10.1021/acssuschemeng.8b06520.

16. Varnava KG, Sarojini V. Making Solid-Phase Peptide Synthesis Greener: A Review of the Literature. Chem - An Asian J 2019, DOI: 10.1002/asia.201801807.

17. Sletten ET, Nuño M, Guthrie D, Seeberger PH. Real-Time Monitoring of SolidPhase Peptide Synthesis Using a Variable Bed Flow Reactor. Chem Commun 2019;55(97):14598-14601, DOI: 10.1039/C9CC08421E.

18. Fuse S, Otake $\mathrm{Y}$, Nakamura H. Peptide Synthesis Utilizing Micro-Flow Technology. Chem - An Asian J 2018;13(24):3818-3832, DOI: 10.1002/asia.201801488. 
19. Fuse S, Masuda K, Otake Y, Nakamura H. Peptide-Chain Elongation Using Unprotected Amino Acids in a Micro-Flow Reactor. Chem - A Eur J 2019;25(66):15091-15097, DOI: 10.1002/chem.201903531.

20. Ollivier N, Toupy T, Hartkoorn RC, Desmet R, Monbaliu JCM, Melnyk O. Accelerated Microfluidic Native Chemical Ligation at Difficult Amino Acids toward Cyclic Peptides. Nat Commun 2018;9(1):1-12, DOI: 10.1038/s41467018-05264-8.

21. Gordon CP. The Renascence of Continuous-Flow Peptide Synthesis-an Abridged Account of Solid and Solution-Based Approaches. Org Biomol Chem 2018;16(2):180-196, DOI: 10.1039/c7ob02759a.

22. Martin FG, Albericio F. Solid Supports for the Synthesis of Peptides From the First Resin Used to the Most Sophisticated in the Market. Chim Oggi 2008;26(4):29-34, DOI: 10.1002/chin.200948243.

23. Santini R, Griffith MC, Qi M. A Measure of Solvent Effects on Swelling of Resins for Solid Phase Organic Synthesis. Tetrahedron Lett 1998;39(49):8951-8954, DOI: 10.1016/S0040-4039(98)02069-3.

24. Dang B, Dhayalan B, Kent SBH. Enhanced Solvation of Peptides Attached to "Solid-Phase" Resins: Straightforward Syntheses of the Elastin Sequence ProGly-Val-Gly-Val-Pro-Gly-Val-Gly-Val. Org Lett 2015;17(14):3521-3523, DOI: 10.1021/acs.orglett.5b01632.

25. Jad YE, Acosta GA, Khattab SN, de la Torre BG, Govender T, Kruger HG, ElFaham A, Albericio F. 2-Methyltetrahydrofuran and Cyclopentyl Methyl Ether for Green Solid-Phase Peptide Synthesis. Amino Acids 2016;48(2):419-426, DOI: $10.1007 / \mathrm{s} 00726-015-2095-x$.

26. Lawrenson S, North M, Peigneguy F, Routledge A. Greener Solvents for SolidPhase Synthesis. Green Chem 2017;19:952-962, DOI: 10.1039/C6GC03147A.

27. Lopez J, Pletscher S, Aemissegger A, Bucher C, Gallou F. N Butylpyrrolidinone as Alternative Solvent for Solid-Phase Peptide Synthesis. Org Process Res Dev 2018;22(4):494-503, DOI: 10.1021/acs.oprd.7b00389.

28. Hansen Solubility Parameters. https://www.hansensolubility.com/index.php?id=11 (accessed Jan 22, 2020).

29. Vaino AR, Janda KD, Torrey N, Road P, Jolla L. Solid-Phase Organic Synthesis: A Critical Understanding of the Resin. J Comb Chem 2000;2:579_ 596, DOI: $10.1021 /$ cc000046o.

30. Analytical Methods in Combinatorial Chemistry, Yan B, Czarnik AW (eds), 2nd Edition. CRC Press, Taylor \& Francis Group: Boca Raton, FL, USA, 2011.

31. Bouillon I, Soural M, Miller MJ, Krchňák V. Resins with Identical Specifications Are Not Identical. Identifying a Useful Solid-Phase Resin. J Comb Chem 2009;11(2):213-215, DOI: 10.1021/cc800143e.

32. Peptides: The Wave of the Future. In Proceedings of the Second International 
and the Seventeenth American Peptide Symposium., Lebl M, A. Houghten R (eds). San Diego, California, USA., 2001; 283-284, DOI: 10.1007/978-94-0100464-0.

33. Engström JUA, Helgee B. Hydrophilic Polymer Supports for Solid-Phase Synthesis: Hydroxyl-Functional Beads of Poly(Vinylpyrrolidone). J Comb Chem 2006;8(3):355-360, DOI: 10.1021/cc050148k.

34. GraphPad PRISM 7 Software https://www.graphpad.com/scientificsoftware/prism/ (accessed Jan 22, 2020).

35. Reilly J. Applied Statistics [Ebook]. Statistical Solutions: Dublin, Ireland, 2017.

36. Hibbert DB, Gooding JJ. Data Analysis For Chemistry. Oxford University Press: New York, NY, USA, 2006.

37. PharmaFactz: Pharmaceutical Calculations - Basic Statistics for Data Analysis. https://pharmafactz.com/pharmaceutical-calculations-basic-statistics-dataanalysis/ (accessed Jan 22, 2020).

38. García-Ramos Y, Paradís-Bas M, Tulla-Puche J, Albericio F. ChemMatrix® for Complex Peptides and Combinatorial Chemistry. J Pept Sci 2010;16(12):675678, DOI: 10.1002/psc.1282.

39. Final Report: Economic Study of Solvent Recycling and Treatment. Environmental Protection Agency. Submitted by The Clean Technology Centre, Cork Institute of Technology. Partners: EPS Consultants, 2010.

40. Raymond MJ, Slater CS, Savelski MJ. LCA Approach to the Analysis of Solvent Waste Issues in the Pharmaceutical Industry. Green Chem 2010;12(10):1826, DOI: 10.1039/c003666h.

41. Clark JH, Tavener SJ. Alternative Solvents: Shades of Green. Org Process Res Dev 2007;11(1):149-155, DOI: 10.1021/op060160g.

42. Sanderson K. It's Not Easy Being Green. Nature 2011;469:18-20, DOI: 10.1038/469018a.

43. Byrne FP, Jin S, Paggiola G, Petchey THM, Clark JH, Farmer TJ, Hunt AJ, Robert McElroy C, Sherwood J. Tools and Techniques for Solvent Selection: Green Solvent Selection Guides. Sustain Chem Process 2016;4(1):1-24, DOI: 10.1186/s40508-016-0051-z.

44. Andraos J. Useful Tools for the Next Quarter Century of Green Chemistry Practice: A Dictionary of Terms and a Data Set of Parameters for High Value Industrial Commodity Chemicals. ACS Sustain Chem Eng 2018;6(3):32063214, DOI: 10.1021/acssuschemeng.7b03360.

45. GraphPad PRISM: Interpreting results - Correlation https://www.graphpad.com/guides/prism/7/statistics/index.htm?stat_interpretin g_results_correlati.htm (accessed Jan 22, 2020).

46. Jad YE, Acosta GA, Govender T, Kruger HG, El-Faham A, de la Torre BG, Albericio F. Green Solid-Phase Peptide Synthesis 2. 2-Methyltetrahydrofuran 
and Ethyl Acetate for Solid-Phase Peptide Synthesis under Green Conditions. ACS Sustain Chem Eng 2016;4(12):6809-6814, DOI:

10.1021/acssuschemeng.6b01765.

47. Kumar A, Jad YE, Collins JM, Albericio F, de la Torre BG. Microwave-Assisted Green Solid-Phase Peptide Synthesis Using y-Valerolactone (GVL) as Solvent. ACS Sustain Chem Eng 2018;6(6):8034-8039, DOI: 10.1021/acssuschemeng.8b01531.

48. Jad YE, Acosta GA, Khattab SN, de la Torre BG, Govender T, Kruger HG, ElFaham A, Albericio F. Peptide Synthesis beyond DMF: THF and ACN as Excellent and Friendlier Alternatives. Org Biomol Chem 2015;13(8):23932398, DOI: 10.1039/C4OB02046D.

49. Sherwood J, De bruyn M, Constantinou A, Moity L, McElroy CR, Farmer TJ, Duncan T, Raverty W, Hunt AJ, Clark JH. Dihydrolevoglucosenone (Cyrene) as a Bio-Based Alternative for Dipolar Aprotic Solvents. Chem Commun 2014;50(68):9650-9652, DOI: 10.1039/c4cc04133j.

50. Magtaan JK, Devocelle M, Kelleher F. Regeneration of Aged DMF for Use in Solid-Phase Peptide Synthesis. J Pept Sci 2019;25(1):e3139, DOI: 10.1002/psc.3139.

51. Přibylka A, Krchňák V, Schütznerová E. Environmentally Friendly SPPS I. Application of $\mathrm{NaOH}$ in 2-MeTHF/Methanol for Fmoc Removal. Green Chem 2019;(Advanced article), DOI: 10.1039/C8GC03778G.

52. Ran Y, Byrne F, Ingram ID V, North M. Resin Swelling in Mixed Solvents Analysed Using Hansen Solubility Parameter Space. Chem - A Eur J 2019;115, DOI: 10.1002/chem.201900228.

53. Pawlas J, Antonic B, Lundqvist M, Svensson T, Finnman J, Rasmussen JH. 2D Green SPPS: Green Solvents for on-Resin Removal of Acid Sensitive Protecting Groups and Lactamization. Green Chem 2019;21(10):2594-2600, DOI: $10.1039 / \mathrm{c9gc00898e.}$

54. Ferrazzano L, Corbisiero D, Martelli G, Tolomelli A, Viola A, Ricci A, Cabri W. Green Solvent Mixtures for Solid-Phase Peptide Synthesis: A

Dimethylformamide-Free Highly Efficient Synthesis of Pharmaceutical-Grade Peptides. ACS Sustain Chem Eng 2019;7(15):12867-12877, DOI: 10.1021/acssuschemeng.9b01766.

55. Sarin VK, Kent SBH, Merrifield RB. Properties of Swollen Polymer Networks. Solvation and Swelling of Peptide-Containing Resins in Solid-Phase Peptide Synthesis. J Am Chem Soc 1980;102(17):5463-5470, DOI: 10.1021/ja00537a006.

56. Dwivedi AK, Mallawaarachchi I, Alvarado LA. Analysis of Small Sample Size Studies Using Nonparametric Bootstrap Test with Pooled Resampling Method. Stat Med 2017;36(14):2187-2205, DOI: 10.1002/sim.7263.

57. Rana S, White P, Bradley M. Influence of Resin Cross-Linking on Solid-Phase Chemistry. J Comb Chem 2001;3(1):9-15, DOI: 10.1021/cc0000592. 
58. Ott RL, Longnecker M. An Introduction to Statistical Methods \& Data Analysis, 7th Edition. Cengage Learning: Boston, MA, USA, 2010.

59. GraphPad PRISM: The difference between correlation and regression https://www.graphpad.com/guides/prism/7/statistics/index.htm?STAT_The_diff erence_between_correla.htm (accessed Jan 22, 2020).

60. Herring C. Biostatistics. In Comprehensive Pharmacy Review for NAPLEX 8th Edition, Shargel L, Mutnick AH, Souney PF, Swanson LN (eds). Lippincott Williams \& Wilkins: Baltimore, MD, USA, 2013.

61. Rumsey DJ. Statistics for Dummies, 2nd Edition. Wiley Publishing Inc.: Indianapolis, IN, USA, 2011.

62. Engström JUA, Helgee B. Functional Beads of Polyvinylpyrrolidone: Promising Support Materials for Solid-Phase Synthesis. Macromol Chem Phys 2006;207(6):605-614, DOI: 10.1002/macp.200500555.

63. LAS EZ Software. https://www.leica-microsystems.com/products/microscopesoftware/details/product/leica-las-ez/ (accessed Jan 22, 2020). 